\title{
A genome-wide association study identifying the SNPs predictive of rapid joint destruction in patients with rheumatoid arthritis
}

\author{
SHINYA HAYASHI ${ }^{1}$, TSUKASA MATSUBARA ${ }^{2}$, KOJI FUKUDA ${ }^{2}$, TOSHIHISA MAEDA $^{1}$, KEIKO FUNAHASHI ${ }^{3}$, \\ MAROWA HASHIMOTO ${ }^{3}$, TOMOYUKI KAMENAGA ${ }^{1}$, YOSHINORI TAKASHIMA ${ }^{1}$ and RYOSUKE KURODA ${ }^{1}$ \\ ${ }^{1}$ Department of Orthopaedic Surgery, Kobe University Graduate School of Medicine, Kobe, Hyogo 650-0017; \\ ${ }^{2}$ Department of Orthopaedic Surgery, Matsubara Mayflower Hospital, Kato, Hyogo 673-1462; \\ ${ }^{3}$ Research Institute of Joint Diseases, Kobe, Hyogo 650-0004, Japan
}

Received July 23, 2020; Accepted December 18, 2020

DOI: $10.3892 /$ br.2021.1407

\begin{abstract}
Rheumatoid arthritis (RA) is a common chronic autoimmune disease leading to joint destruction. The aim of the present study was to identify the genomic factors predictive of susceptibility to joint destruction in patients with RA by performing a genome-wide association study of genetic variants, including single nucleotide polymorphisms (SNPs). The study sample included 228 patients with a diagnosis of RA in the past 5 years. Patients were classified into rapid (total Sharp score/years of RA, $\geq 50$ ) and slow (total Sharp score/years of $\mathrm{RA},<50)$ joint destruction groups for analysis. The association between the genome-wide SNP analysis and joint destruction was evaluated. The following SNPs were strongly associated with rapid radiographic joint destruction: $r$ s2295926 $\left(\mathrm{P}<1 \times 10^{-7}\right)$, belonging to the $N$-acetylgalactosaminyltransferase 12 (GALNT12) gene and rs11958855 $\left(\mathrm{P}<1 \times 10^{-6}\right)$, belonging to the $K C N N 2$ gene (associated with the potassium calcium-activated channel subfamily). The identification of genetic predictors of rapid joint destruction in RA (GALNT12 and KCNN2) may provide information regarding potential therapeutic targets, and this information may be used to assist in the management RA disease progression, thereby improving the functional outcomes for patients.
\end{abstract}

\section{Introduction}

Rheumatoid arthritis (RA) is an autoimmune disease characterized by chronic inflammation of the synovial lining of the joint (1), with progressive joint destruction and systemic complications being commonly observed (2). The prevalence rate of RA has been estimated to range between

Correspondence to: Dr Shinya Hayashi, Department of Orthopaedic Surgery, Kobe University Graduate School of Medicine, 7-5-1 Kusunoki-cho, Chuo-ku, Kobe, Hyogo 650-0017, Japan

E-mail: shayashi@med.kobe-u.ac.jp

Key words: genome-wide screening, rheumatoid arthritis, Sharp/van der Heijde score, single nucleotide polymorphisms
0.5 and $1.0 \%$ (3). As an autoimmune disease, $70-80 \%$ of the patients with RA possess auto-antibodies, such as rheumatoid factor or anti-citrullinated protein antibodies (ACPA) (4). Early aggressive disease-modifying antirheumatic drug therapy can improve the clinical outcomes of patients with RA, including a decrease in long-term radiographic progression, and anti-TNF therapy can alter the natural progression of RA (5). Therefore, identifying patients at high risk of severe RA is important, such that more suitable treatments can be offered earlier on, thereby improving their disease prognosis (6).

Genetic polymorphisms may serve as useful markers of RA disease prognosis $(7,8)$. To date, polygenic risk scores have largely been used to predict RA disease progression in humans (7), although other genomic predictive approaches using animal models or statistical methods have also been described $(9,10)$. However, the International HapMap Project, which defines variations in the map of the human genome (11), has allowed genome-wide association screening (GWAS) of genetic variants, including single nucleotide polymorphisms (SNPs) (12). As an example, through GWAS, PADI4 was identified as a non-major-histocompatibility complex genomic locus predictive of RA in a Japanese population (13). GWAS meta-analyses provided further evidence of a shared genetic background amongst patients with RA across different populations $(14,15)$. A large-scale GWAS meta-analysis in a Japanese population of patients with RA identified the following new RA risk loci: B3GNT2, ANXA3, CSF2, CD83, NFKBIE, ARID5B, PDE2A-i PLD4 and PTPN2 (16).

Clinically, radiological damage provides an objective measure of RA severity; with joint destruction quantified using radiographic scores, such as the Sharp/van der Heijde score (SHS), which reflects the inflammatory status of the joint (17). Only a few studies to date have evaluated the association between radiographic joint destruction and genetic analysis. Rodriguez-Rodriguez et al (18) reported a probable association between the prostaglandin E receptor 4 variant, rs76523431 and radiographic joint destruction in Caucasian patients with RA. Suzuki et al (19) reported an association between the PADI4 risk allele and radiographic joint destruction amongst Japanese patients with RA. However, GWAS has not previously been used to identify risk factors of radiographic joint destruction. Therefore, the purpose of the present study was 
to identify genomic factors predictive of susceptibility to joint destruction in patients with RA by performing a GWAS of genetic variants, including SNPs.

\section{Patients and methods}

Ethics statement and patient consent. The methods used in the present study were approved by the Research Institute of Joint Disease Kobe on June 11, 2008. All patients included in the study satisfied the American College of Rheumatology 1987 revised criteria for RA (20) and completed the genetic analysis in the Patient Registry. A total of 240 patients were recruited, all of whom provided written informed consent in Matsubara Mayflower Hospital between October 2008 and December 2012. Additionally, another group of 228 patients (median age, 55 years old; age range, 23-84 years; 49 males and 179 females) were recruited between January 2013 and September 2017. Data collection, including blood examination and x-rays of the 240 patients (median age 60 years old; age range 21-83 years; 45 males and 195 females), was performed in the Matsubara Mayflower Hospital between January 2009 and December 2012. In the second group of 228 patients, data collection was performed between January 2013 and December 2017. All DNA samples were included in the Japanese GWAS analysis.

Radiographic evaluation. Radiographs of the hands and feet were scored according to the Sharp method (17). All radiographic data included in the analysis were obtained within 5 years of RA diagnosis, and clinical data and blood samples were collected on the same day as the diagnosis. In total, 228 radiographs (228 patients) were scored by a single experienced examiner who was blinded with respect to the clinical and genetic data. A total of 16 and 6 areas were considered for assessing erosions and joint space narrowing (JSN) for the hands and feet, respectively (Fig. 1). Erosions were scored as follows: 1, discrete but clearly present; 2 or 3 , larger, dependent on the surface area of the joint involved. A score of 3 was given if the erosion was large and extended over the imaginary middle of the bone. A score of 5 was given if a complete collapse of the joint was observed or if the entirety of the joint was affected. In each joint, individual erosions were totaled, up to a maximum of 5 (Fig. 1). For JSN, a normal joint space was scored 0 . A score of 2 indicated focal narrowing of the joint. A score of 1 was not used when the reviewer was unsure whether there was joint space narrowing. A generalized narrowing leaving $>50 \%$ of the original joint space present was scored as 2 . A generalized narrowing leaving $<50 \%$ of the original joint space present was scored as 3 . A subluxation of the joint was also scored as 3. A bony ankylosis or a complete luxation of the joint was scored as 4 (Fig. 1). The maximum erosion score of the hands and wrists was 160 and that of the feet was 120 (maximum total erosion score, 280). Accordingly, the maximum JSN score of the hands and wrists was 120 and that of the feet was 48 (maximum total JSN score, 168). The sum of the erosion and JSN scores was the total SHS (maximum, 448). Radiographic joint destruction was quantified as the total SHS score divided by the duration of RA.

To avoid bias in the RA duration, radiographic joint destruction was quantified as the total SHS score divided by the duration of RA. A previous study defined the remission

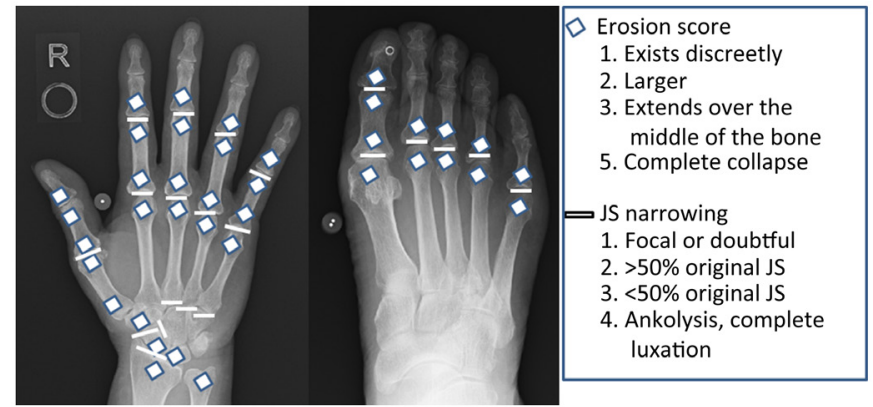

Figure 1. Sharp/van der Heijde score scoring system. JS, joint space.

of joint destruction as changes from baseline of $<0.5$ points per year and rapid joint destruction as changes from baseline to $>5$ points per year (21). However, the SHS score change from baseline because was not determined as radiographical data was collected at the time of blood sample collection. The ATTRACT trial showed that an SHS of $>90$ points indicated a high degree of joint destruction within 3 years of RA diagnosis (22). Furthermore, the patient populations in the present study with high disease activity based on DAS 28 (C-reactive protein) $>5.1(15.6 \%)$ and populations with over 50 points SHS/year (13.2\%) were similar to that observed in the ATTRACT trial. Therefore, $>50$ points of SHS/year was defined as rapid joint destruction. Patients were assigned to either the rapid joint destruction group (defined as total SHS/year $\geq 50$ ) or the slow joint destruction group (defined by a total SHS/year <50).

Genome-wide SNP analysis and association study. Samples of $7 \mathrm{ml}$ venous blood were drawn into glass tubes and stored at $4^{\circ} \mathrm{C}$ until required for DNA extraction at Mitsubishi BCL, Inc. DNA samples were prepared using a Gentra Puregene DNA isolation kit according to the manufacturer's protocol (cat. no. 158489; Qiagen, GmbH). DNA integrity was assessed using a Nanodrop 2000 spectrophotometer (Thermo Fisher Scientific, Inc.) to determinate the OD260/280 ratio (acceptable range, 1.82-1.92) and the concentration of the total DNA (acceptable range, $8-28 \mu \mathrm{g} / \mathrm{ml}$ ), and all the samples were deemed to be of sufficient quality $(2.0>0 D 260 / 280>1.8$; DNA concentration $>5 \mu \mathrm{g} / \mathrm{ml}$ ). Furthermore, the integrity of the DNA was assessed by loading $100 \mathrm{ng}$ per sample on a $0.75 \%$ agarose gel and comparing separation of the full length DNA band.

Genome-wide SNP genotyping was performed by deCode Genetics Inc. using the Illumina HumanHap300K chip technology (Illumina, Inc.). The genotyping of 317,503 SNPs was performed, including a quality control analysis. SNP genotyping was performed using an Infinium OmniExpressExome-8 Bead Chip kit (cat. no. 20024676; Illumina, Inc.) according to the manufacturer's protocol. SNP genotyping calling and quality control for samples and SNPs were performed using Illumina GenomeStudio version 2011 (Illumina, Inc.) and a cluster file. Genotypes were scored using GenomeStudio using a GenCall threshold of 0.15. Samples were accepted when their call rates were $>98 \%$. SNPs were excluded if they: i) Had an R mean value in at least 1 of 3 clusters $<0.25$; ii) Cluster Sep values $<0.4$; or iii) the number of no calls value was $>2$ on all chromosomes except for the $\mathrm{Y}$ chromosome. 
Table I. Clinicopathological characteristics.

\begin{tabular}{|c|c|c|c|}
\hline Factor & $\begin{array}{c}\mathrm{TSS} \geq 50 \\
\mathrm{n}=30\end{array}$ & $\begin{array}{c}\text { TSS }<50 \\
n=198\end{array}$ & P-value \\
\hline \multicolumn{4}{|l|}{ Sex, N (\%) } \\
\hline Male & $4(13)$ & $45(22.8)$ & \\
\hline Female & $26(87)$ & $153(77.2)$ & 0.243 \\
\hline Age, years & $58.1 \pm 12.5$ & $54.1 \pm 13.0$ & 0.227 \\
\hline RA duration (years) & $1.4 \pm 1.1$ & $3.6 \pm 1.2$ & $<0.001^{\mathrm{c}}$ \\
\hline IgM RF titer, IU/ml & $62.6 \pm 65.8$ & $63.1 \pm 60.9$ & 0.992 \\
\hline ACPA titer, IU/ml & $81.3 \pm 66.0$ & $83.9 \pm 69.2$ & 0.982 \\
\hline \multicolumn{4}{|l|}{ Stage, N $(\%)$} \\
\hline 1 & $2(6.7)$ & $35(17.7)$ & 0.127 \\
\hline 2 & $6(20.0)$ & $72(36.4)$ & 0.078 \\
\hline 3 & $12(40.0)$ & $56(28.3)$ & 0.196 \\
\hline 4 & $10(33.3)$ & $35(17.7)$ & $0.045^{\mathrm{a}}$ \\
\hline \multicolumn{4}{|l|}{ Class (\%) } \\
\hline 1 & $4(13.3)$ & $61(16.7)$ & 0.143 \\
\hline 2 & $17(56.7)$ & $115(58.0)$ & 0.884 \\
\hline 3 & $9(4.3)$ & $22(10.1)$ & $0.005^{\mathrm{b}}$ \\
\hline 4 & $0(0.0)$ & $0(0.0)$ & 1 \\
\hline $\begin{array}{l}\text { DAS } 28, C \text {-reactive } \\
\text { protein }\end{array}$ & $4.1 \pm 1.9$ & $4.6 \pm 1.6$ & 0.298 \\
\hline Total sharp score/year & $101.3 \pm 69.6$ & $20.3 \pm 18.3$ & $<0.001^{\mathrm{c}}$ \\
\hline
\end{tabular}

After exclusion based on these criteria, 278,347 SNPs were retained in the case-control analysis.

Statistical analysis. Demographic and clinicopathological characteristics of patients assigned to the rapid and slow joint destruction groups were compared using a one-way ANOVA for continuous variables (such as age and RA duration). Bonferroni's correction was used for multiple comparisons. A contingency table for categorical data (Steinbrocker stage and class) was analyzed using a $\chi^{2}$ test. The frequency of minor allele homo combinations of SNPs were compared between the rapid and slow joint destruction groups for 277,339 SNPs using a Fisher's exact test in Plink (23). The frequency of the minor allele homo combinations between the rapid and slow joint destruction groups for another 240 samples using the genotyping data of 178,748 SNPs to confirm the results obtained for the 228 samples using genotyping data of 317,503 SNPs. $\mathrm{P}<0.05$ was considered to indicate a statistically significant difference.

\section{Results}

Patient characteristics. Among the 228 patients enrolled in the study, 30 patients were included in the rapid joint destruction group (group A), and 198 patients were classified into the slow joint destruction group (group B). There was no significant difference in the distribution of sex, age, titer of IgM RF, titer of ACPA and DAS28 (C-reactive protein)
Table II. Patients characteristics of the second cohort of 240 samples.

\begin{tabular}{|c|c|c|c|}
\hline Factor & $\begin{array}{c}\mathrm{TSS} \geq 50 \\
\mathrm{n}=32\end{array}$ & $\begin{array}{c}\mathrm{TSS}<50 \\
\mathrm{n}=208\end{array}$ & $\mathrm{P}$-value \\
\hline \multicolumn{4}{|l|}{ Sex, N (\%) } \\
\hline Male & $7(21.9)$ & $38(18.3)$ & \\
\hline Female & $25(78.1)$ & $170(81.7)$ & 0.306 \\
\hline Age, years & $57.5 \pm 16.0$ & $61.0 \pm 12.4$ & 0.316 \\
\hline RA duration (years) & $1.4 \pm 1.1$ & $2.2 \pm 1.6$ & 0.014 \\
\hline IgM RF titer, IU/ml & $60.1 \pm 70.1$ & $68.3 \pm 64.2$ & 0.919 \\
\hline ACPA titer, IU/ml & $86.1 \pm 60.9$ & $79.1 \pm 61.8$ & 0.816 \\
\hline \multicolumn{4}{|l|}{ Stage, N (\%) } \\
\hline 1 & $2(6.2)$ & $36,17.3 \%$ & 0.111 \\
\hline 2 & $4(12.5)$ & $80,38.5 \%$ & $0.004^{t}$ \\
\hline 3 & $15(46.9)$ & $61,29.3 \%$ & $0.047^{\circ}$ \\
\hline 4 & $11(34.4)$ & $31,14.9 \%$ & 0.007 \\
\hline \multicolumn{4}{|l|}{ Class $(\%)$} \\
\hline 1 & $5(15.6)$ & $22(10.6)$ & 0.143 \\
\hline 2 & $20(62.5)$ & 149 (71.6) & 0.15 \\
\hline 3 & $5(15.6)$ & $37(17.8)$ & 0.982 \\
\hline 4 & $0(0.0)$ & $0(0.0)$ & 1 \\
\hline DAS 28, C-reactive & $4.1 \pm 1.9$ & $4.7 \pm 1.6$ & 0.251 \\
\hline
\end{tabular}

protein

Total sharp score/year $\quad 115.6 \pm 59.1 \quad 19.4 \pm 11.4<0.001^{\mathrm{c}}$

${ }^{\mathrm{a}} \mathrm{P}<0.05, \quad{ }^{\mathrm{b}} \mathrm{P}<0.01,{ }^{\mathrm{c}} \mathrm{P}<0.001$. RA, rheumatoid arthritis; ACPA, anti-citrullinated protein antibodies; TSS, total SHS score/year.

between groups A and B (Table I). The RA duration, number of patients classed as Steinbrocker 3, and total SHS score/year (TSS) were significantly higher in group A compared with group B. Amongst the other 240 samples enrolled in the study, 32 patients were included in the rapid joint destruction group (group C), and 204 patients were classified into the slow joint destruction group (group D). The RA duration, number of patients classed as Steinbrocker 2, 3 or 4, as well as TSS were significantly higher in group C compared with group D (Table II). The patient's characteristics were similar between the two sets of patients.

Analysis of genetic association with joint destruction. Several SNPs were identified that were strongly associated with rapid radiographic joint destruction (Figs. 2 and 3). Using a Manhattan plot. SNPs that were significantly different between the rapid and slow joint destruction groups were identified; all of which had a different chromosomal locus (Figs. 2 and 3). A focus was placed on SNPs with smaller P-values $<1 \times 10^{-6}$. The selected SNPs, shown in Table III, were as follows: one minor allele homo SNP with a P-value difference between groups A and B of $1 \times 10^{-7.24}$ (rs2295926 located on chromosome 9; gene symbol name, GALNT12); gene location, intron), and another minor allele homo SNP with a P-value difference of $1 \times 10^{-6.64}$ (rs11958855 located on chromosome 5; gene symbol name, KCNN2; gene location, intron). The same minor allele homo 


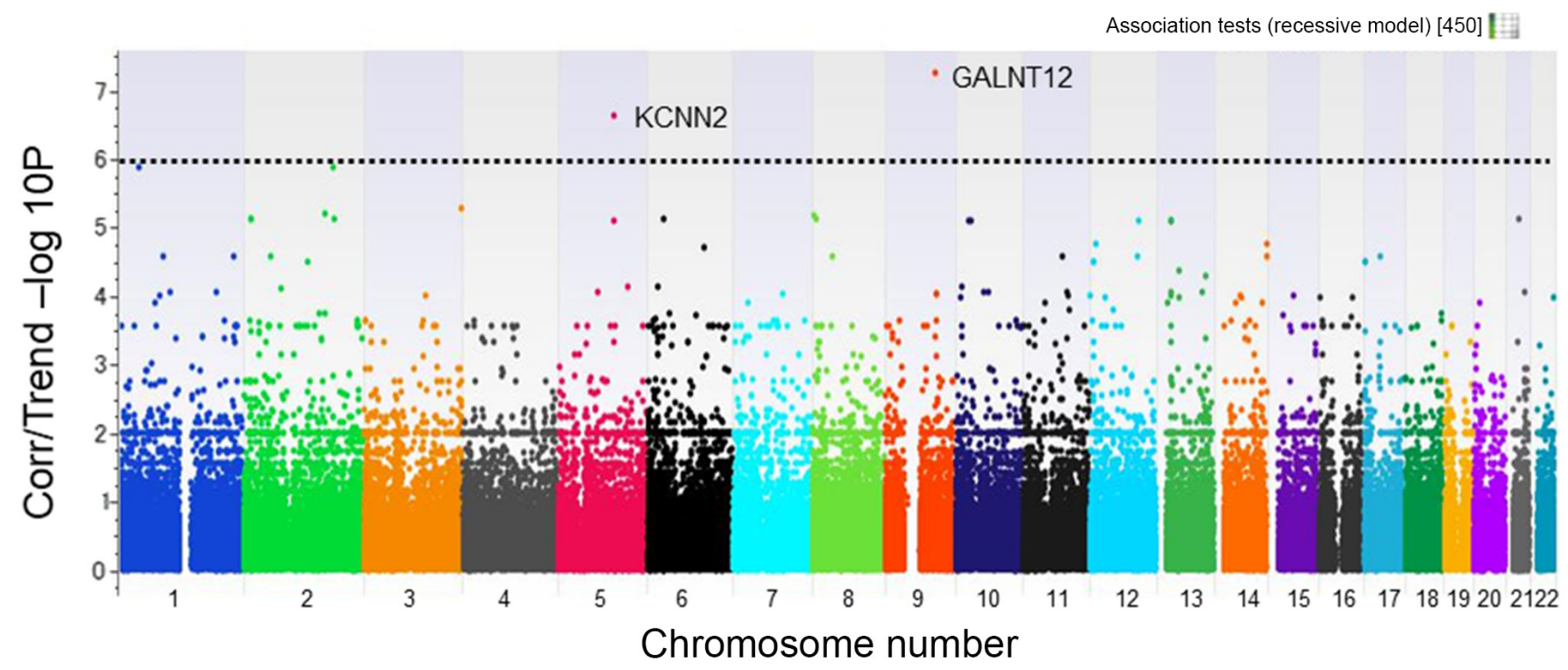

Figure 2. Manhattan plot, showing the difference in SNPs between the rapid (total SHS score/year, $\geq 50$ ) and slow (total SHS score/year, $<50$ ) joint destruction groups. Dotted line indicates thresholds for significance $\left(\mathrm{P}<1 \times 10^{-6}\right)$. X-axis, chromosome number. Y-axis, $\log _{10}{ }^{-\mathrm{P}}$. SHS, Sharp/van der Heijde score; SNP, single nucleotide polymorphism.

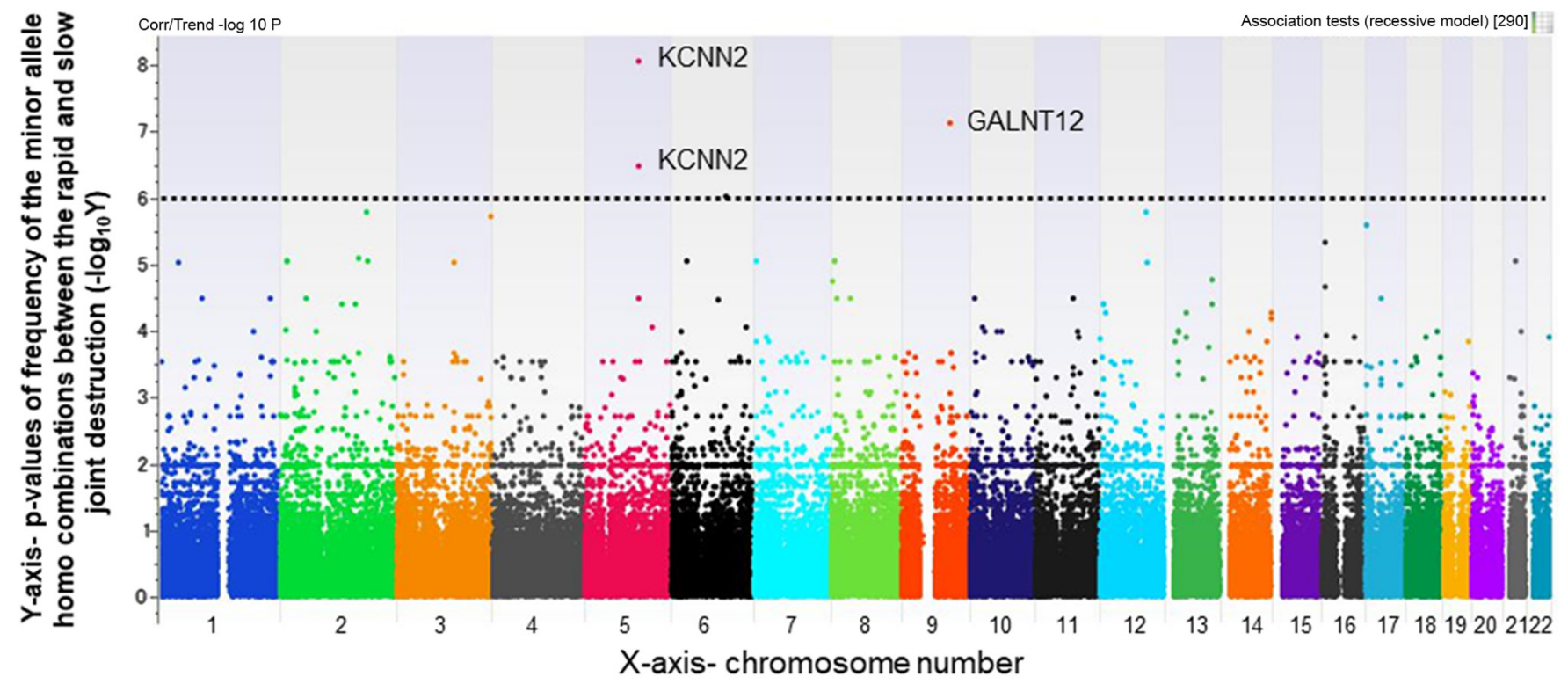

Figure 3. Manhattan plot of the 240 samples, showing the difference in SNPs between the rapid (total SHS score/year, $\geq 50$ ) and slow (total SHS score/year, $<50$ ) joint destruction groups. Dotted line indicates thresholds for significance $\left(\mathrm{P}<1 \times 10^{-6}\right)$. X-axis, chromosome number. Y-axis, $\log _{10}{ }^{-\mathrm{P}}$. SHS, Sharp/van der Heijde score; SNP, single nucleotide polymorphism.

SNPs rs2295926 (GALNT12) and two SNPs of rs11958855 and rs36963 in $K C N N 2$ gene were detected between the groups C and D (rs2295926; $\mathrm{P}=1 \times 10^{-7.11}$, rs11958855; $\left.\mathrm{P}=1 \times 10^{-8.05}, \mathrm{rs} 36963 ; \mathrm{P}=1 \times 10^{-6.46}\right)$ in the genotyping results of 178,748 SNPs (Table IV).

\section{Discussion}

In the present study, various SNPs were first identified as novel risk loci which may be used to predict susceptibility to joint destruction in patients with RA. The risk loci identified were rs2295926, an intronic SNP of the GALNT12 gene located on chromosome 9, and rs11958855, an intronic SNP of the KCNN2 gene located on chromosome 5.

GALNT12 belongs to a family of hexosyltransferases, which are involved in the initial steps of the mucin-type O-glycosylation (24). Activity of these enzymes can lead to aberrant glycosylation, and this is associated with alterations in cell growth, differentiation, transformation, adhesion, metastasis and immune surveillance in several types of cancer (25). GALNT12 expression is upregulated in the digestive tract (24), and is frequently downregulated in colorectal cancer (26). Glycosaminoglycans are proteoglycans that are involved in the regulation of the diffusion of growth factors, and can also bind 
Table III. Single nucleotide polymorphisms associated with rapid joint destruction in the first cohort of 228 patients.

\begin{tabular}{|c|c|c|c|c|c|}
\hline$-\log _{10}(\mathrm{P}$-value $)$ & Name & Chromosome & Gene symbol & Gene description & $\begin{array}{l}\text { Gene } \\
\text { location }\end{array}$ \\
\hline 7.24 & rs2295926 & 9 & GALNT12 & Polypeptide $\mathrm{N}$-acetylgalactosaminyltransferase 12 & Intron \\
\hline 6.64 & rs11958855 & 5 & $\mathrm{KCNN} 2$ & $\begin{array}{l}\text { Potassium calcium-activated channel } \\
\text { subfamily } \mathrm{N} \text { member } 2\end{array}$ & Intron \\
\hline 5.88 & rs4266846 & 1 & LOC105378657 & Uncharacterized LOC105378657 & $\begin{array}{l}\text { Non-coding } \\
\text { RNA }\end{array}$ \\
\hline 5.88 & rs 13029379 & 2 & SCHLAP1 & $\begin{array}{l}\text { SWI/SNF complex antagonist associated } \\
\text { with prostate cancer } 1\end{array}$ & Intron \\
\hline 5.28 & rs7629215 & 3 & LOC105374287 & Uncharacterized LOC105374287 & $\begin{array}{l}\text { Non-coding } \\
\text { RNA }\end{array}$ \\
\hline 5.19 & rs 355808 & 2 & COBLL1 & Cordon-blue $\mathrm{WH} 2$ repeat protein like 1 & Intron \\
\hline 5.18 & rs7357519 & 8 & CSMD1 & CUB and Sushi multiple domains 1 & Intron \\
\hline 5.11 & rs4669995 & 2 & TRIB2/FAM84A & $\begin{array}{l}\text { Tribbles homolog } 2 \text { (Drosophila)/ } \\
\text { family with sequence similarity } 84 \text {, } \\
\text { member A }\end{array}$ & Intergenic \\
\hline 5.11 & rs 10181834 & 2 & TRIB2/FAM84A & $\begin{array}{l}\text { Tribbles homolog } 2 \text { (Drosophila)/ } \\
\text { family with sequence similarity } 84 \text {, } \\
\text { member A }\end{array}$ & Intergenic \\
\hline 5.11 & rs 833126 & 2 & PDE1A & Phosphodiesterase 1A & Intron \\
\hline
\end{tabular}

Table IV. Single nucleotide polymorphisms associated with rapid joint destruction in the second cohort of 240 patients.

\begin{tabular}{|c|c|c|c|c|c|}
\hline$-\log _{10}(\mathrm{P}$-value $)$ & Name & Chromosome & Gene symbol & Gene description & $\begin{array}{l}\text { Gene } \\
\text { location }\end{array}$ \\
\hline 8.05 & rs 11958855 & 5 & $\mathrm{KCNN} 2$ & $\begin{array}{l}\text { Potassium calcium-activated channel } \\
\text { subfamily } \mathrm{N} \text { member } 2\end{array}$ & Intron \\
\hline 7.11 & rs2295926 & 9 & GALNT12 & Polypeptide N-acetylgalactosaminyltransferase 12 & Intron \\
\hline 6.46 & rs36963 & 5 & KCNN2 & $\begin{array}{l}\text { Potassium calcium-activated channel } \\
\text { subfamily } \mathrm{N} \text { member } 2\end{array}$ & Intron \\
\hline 6.02 & rs 1539403 & 6 & $\begin{array}{l}\text { LOC100128588/ } \\
\text { RFPL4B }\end{array}$ & $\begin{array}{l}\text { Uncharacterized LOC } 100128588 / \\
\text { PIN2/TERF1 interacting, telomerase } \\
\text { inhibitor } 1 \text { pseudogene/ret finger } \\
\text { protein-like } 4 \mathrm{~B}\end{array}$ & Intergenic \\
\hline 5.77 & rs 13029379 & 2 & SCHLAP1 & $\begin{array}{l}\text { SWI/SNF complex antagonist } \\
\text { associated with prostate cancer } 1\end{array}$ & Intron \\
\hline 5.77 & rs 1582341 & 12 & NEDD1/RMST & $\begin{array}{l}\text { Neural precursor cell expressed, } \\
\text { developmentally down-regulated } 1 / \\
\text { rhabdomyosarcoma } 2 \text { associated } \\
\text { transcript (non-protein coding) }\end{array}$ & Intergenic \\
\hline 5.71 & rs7629215 & 3 & LOC105374287 & $\begin{array}{l}\text { Uncharacterized } \\
\text { LOC } 105374287\end{array}$ & $\begin{array}{l}\text { Non-coding } \\
\text { RNA }\end{array}$ \\
\hline 5.57 & rs2644714 & 17 & VPS53/FAM57A & $\begin{array}{l}\text { Vacuolar protein sorting } 53 \\
\text { homolog }(\text { S. cerevisiae }) / \\
\text { family with sequence similarity } 57 \text {, } \\
\text { member A }\end{array}$ & Intergenic \\
\hline 5.57 & rs2295479 & 17 & TLCD3A & TLC domain containing $3 \mathrm{~A}$ & Intron \\
\hline 5.33 & rs 12447219 & 16 & RBFOX1 & RNA binding fox-1 homolog 1 & Intron \\
\hline
\end{tabular}

different functional proteins, such as fibroblast growth factors and hedgehog proteins, thereby modulating various signaling pathways (27,28). Mucin-type O-glycosylation consists of glycans attached via O-linked $N$-acetyl-D-galactosamine 
to serine and threonine residues, and it is one of the most abundant types of protein glycosylation in animals, where it is controlled by a large family of GALNT genes (29). GALNT12 and GALNT3 regulate mucin-type O-glycosylation (24). Therefore, GALNT12 may serve a role in cartilage homeostasis, and the rs2295926 SNP may serve a significant role in rapid joint destruction in patients with $\mathrm{RA}$.

The SNP rs11958855 was identified as having a genome-wide significant association with rapid joint destruction in RA. rs11958855 is an intergenic SNP of the KCNN2 gene located on chromosome 5. KCNN2 encodes an integral membrane protein that forms small conductance calcium-activated potassium (SK) channels. SK2 channels are voltage-independent $\mathrm{Ca}^{2+}$-activated $\mathrm{K}^{+}$channels. In neurons of the central nervous system, activation of these channels modulates neuronal excitability by hyperpolarizing the membrane (30). Regarding cartilage homeostasis, low conductance-potassium calcium-activated channel transcript subtype SK1 (KCNN1, KCa2.1) and SK3 (KCNN3, $\mathrm{KCa} 2.3$ ) and intermediate potassium calcium-activated channel transcript subtypes (IK, KCNN4, SK4 and KCa3.1) have been shown to be expressed in OUMS-27 cells (a chondrosarcoma cell line). SK channels have been proposed to be involved in the response to osmotic change in chondrocytes (31). SK channels also provide a direct link between inflammation and chondrocyte function (31). SK2 was not expressed in normal cartilage tissues (31), but it may be expressed and have a function related to inflammation in cartilage tissues of patients with RA.

The present study has some limitations. First, the actual effects of these genetic variants were not assessed in vitro or in vivo. Further studies are necessary to fully elucidate the effects of these and other SNPs. Second, SHS was assessed by a single examiner, which may have led to a potential bias. The cohorts were comprised entirely of Japanese patients; SNPs may differ in subjects of different ethnicities. Finally, the SHS score change from the baseline was not evaluated as only radiographical data was collected at the time of blood sample collection; however, previous reports have defined rapid joint destruction as changes from baseline of $>5$ points per year.

In conclusion, the rs 2295926 SNP variant in the GALNT12 gene and rs11958855 in the KCNN2 gene may be associated with rapid joint destruction amongst Japanese patients with RA. At present, there are no means of managing RA with the aim of reducing joint destruction. Therefore, the identification of genetic predictors of rapid joint destruction in RA (GALNT12 and KCNN2) may highlight potentially novel therapeutic targets to improve management of disease progression, thereby improving the quality of life of patients.

\section{Acknowledgements}

Not applicable.

\section{Funding}

No funding was received.

\section{Availability of data and materials}

The datasets generated and/or analyzed during the present study are not publicly available due to an application for a patent in Japan (patent no. 4869834, registration date Nov 25, 2011) but are available from the corresponding author upon reasonable request.

\section{Authors' contributions}

SH, RK and TsM designed the study. All authors were involved in drafting and revising the manuscript. $\mathrm{KoF}, \mathrm{SH}, \mathrm{KeF}$, ToM, TK, MH and YT participated in data collection. SH, TsM and $\mathrm{KeF}$ confirm the authenticity of all the raw data. All authors read and approved the final manuscript.

\section{Ethics approval and consent to participate}

The methods used in the present study were approved by the Research Institute of Joint Disease Kobe on June 11, 2008. All patients provided written informed consent for participation.

\section{Patient consent for publication}

Not applicable.

\section{Competing interests}

The authors declare that they have no competing interests.

\section{References}

1. Klareskog L, Catrina AI and Paget S: Rheumatoid arthritis. Lancet 373: 659-672, 2009.

2. Radner H, Smolen JS and Aletaha D: Comorbidity affects all domains of physical function and quality of life in patients with rheumatoid arthritis. Rheumatology (Oxford) 50: 381-388, 2011.

3. Myasoedova E, Crowson CS, Kremers HM, Therneau TM and Gabriel SE: Is the incidence of rheumatoid arthritis rising?: Results from Olmsted County, Minnesota, 1955-2007. Arthritis Rheum 62: 1576-1582, 2010.

4. Smolen JS, Aletaha D, Barton A, Burmester GR, Emery P, Firestein GS, Kavanaugh A, McInnes IB, Solomon DH, Strand V, et al: Rheumatoid arthritis. Nat Rev Dis Primers 4: 18001, 2018.

5. Breedveld F: The value of early intervention in RA - a window of opportunity. Clin Rheumatol 30 (Suppl 1): S33-S39, 2011.

6. van Nies JA, Krabben A, Schoones JW, Huizinga TW, Kloppenburg $\mathrm{M}$ and van der Helm-van Mil AH: What is the evidence for the presence of a therapeutic window of opportunity in rheumatoid arthritis? A systematic literature review. Ann Rheum Dis 73: 861-870, 2014.

7. Dudbridge F: Power and predictive accuracy of polygenic risk scores. PLoS Genet 9: e1003348, 2013. Erratum in: PLoS Genet: doi: 10.1371/annotation/b91ba224-10be-409d-93f4$7423 \mathrm{~d} 502 \mathrm{cba} 0$.

8. Spiliopoulou A, Nagy R, Bermingham ML, Huffman JE, Hayward C, Vitart V, Rudan I, Campbell H, Wright AF, Wilson JF, et al: Genomic prediction of complex human traits: Relatedness, trait architecture and predictive meta-models. Hum Mol Genet 24: 4167-4182, 2015.

9. Abraham G, Kowalczyk A, Zobel J and Inouye M: Performance and robustness of penalized and unpenalized methods for genetic prediction of complex human disease. Genet Epidemiol 37: 184-195, 2013.

10. Warren H, Casas JP, Hingorani A, Dudbridge F and Whittaker J: Genetic prediction of quantitative lipid traits: Comparing shrinkage models to gene scores. Genet Epidemiol 38: 72-83, 2014.

11. International HapMap Consortium: The International HapMap Project. Nature 426: 789-796, 2003.

12. Ozaki K, Ohnishi Y, Iida A, Sekine A, Yamada R, Tsunoda T, Sato H, Sato H, Hori M, Nakamura Y, et al: Functional SNPs in the lymphotoxin-alpha gene that are associated with susceptibility to myocardial infarction. Nat Genet 32: 650-654, 2002. 
13. Suzuki A, Yamada R, Chang X, Tokuhiro S, Sawada T, Suzuki M, Nagasaki M, Nakayama-Hamada M, Kawaida R, Ono M, et al: Functional haplotypes of PADI4, encoding citrullinating enzyme peptidylarginine deiminase 4 , are associated with rheumatoid arthritis. Nat Genet 34: 395-402, 2003.

14. Traylor M, Knevel R, Cui J, Taylor J, Harm-Jan W, Conaghan PG, Cope AP, Curtis C, Emery P, Newhouse S, et al: Genetic associations with radiological damage in rheumatoid arthritis: Meta-analysis of seven genome-wide association studies of 2,775 cases. PLoS One 14: e0223246, 2019.

15. Zeng Z, Zhang W, Qian Y, Huang H, Wu DJH, He Z, Ye D, Mao Y and Wen C: Association of telomere length with risk of rheumatoid arthritis: A meta-analysis and Mendelian randomization. Rheumatology (Oxford) 59: 940-947, 2020.

16. Okada Y, Terao C, Ikari K, Kochi Y, Ohmura K, Suzuki A, Kawaguchi T, Stahl EA, Kurreeman FA, Nishida N, et al: Meta-analysis identifies nine new loci associated with rheumatoid arthritis in the Japanese population. Nat Genet 44: 511-516, 2012.

17. Sharp JT, Young DY, Bluhm GB, Brook A, Brower AC Corbett M, Decker JL, Genant HK, Gofton JP, Goodman N, et al: How many joints in the hands and wrists should be included in a score of radiologic abnormalities used to assess rheumatoid arthritis? Arthritis Rheum 28: 1326-1335, 1985.

18. Rodriguez-Rodriguez L, Ivorra-Cortes J, Carmona FD, Martín J, Balsa A, van Steenbergen HW, van der Helm-van Mil AH, González-Álvaro I and Fernandez-Gutiérrez B: PTGER4 gene variant rs76523431 is a candidate risk factor for radiological joint damage in rheumatoid arthritis patients: A genetic study of six cohorts. Arthritis Res Ther 17: 306, 2015.

19. Suzuki T, Ikari K, Yano K, Inoue E, Toyama Y, Taniguchi A, Yamanaka $\mathrm{H}$ and Momohara S: PADI4 and HLA-DRB1 are genetic risks for radiographic progression in RA patients, independent of ACPA status: Results from the IORRA cohort study. PLoS One 8: e61045, 2013.

20. Arnett FC, Edworthy SM, Bloch DA, McShane DJ, Fries JF, Cooper NS, Healey LA, Kaplan SR, Liang MH, Luthra HS, et al: The American Rheumatism Association 1987 revised criteria for the classification of rheumatoid arthritis. Arthritis Rheum 31: 315-324, 1988.

21. Vastesaeger N, Xu S, Aletaha D, St Clair EW and Smolen JS: A pilot risk model for the prediction of rapid radiographic progression in rheumatoid arthritis. Rheumatology (Oxford) 48 : 1114-1121, 2009.

22. Lipsky PE, van der Heijde DM, St Clair EW, Furst DE, Breedveld FC, Kalden JR, Smolen JS, Weisman M, Emery P, Feldmann M, et al; Anti-Tumor Necrosis Factor Trial in Rheumatoid Arthritis with Concomitant Therapy Study Group: Infliximab and methotrexate in the treatment of rheumatoid arthritis. N Engl J Med 343: 1594-1602, 2000.
23. Purcell S, Neale B, Todd-Brown K, Thomas L, Ferreira MA, Bender D, Maller J, Sklar P, de Bakker PI, Daly MJ, et al: PLINK: A tool set for whole-genome association and population-based linkage analyses. Am J Hum Genet 81: 559-575, 2007.

24. Guo JM, Zhang Y, Cheng L, Iwasaki H, Wang H, Kubota T, Tachibana $\mathrm{K}$ and Narimatsu $\mathrm{H}$ : Molecular cloning and characterization of a novel member of the UDP-GalNAc:polypeptide $\mathrm{N}$-acetylgalactosaminyltransferase family, pp-GalNAc-T12. FEBS Lett 524: 211-218, 2002.

25. Brockhausen I: Mucin-type O-glycans in human colon and breast cancer: Glycodynamics and functions. EMBO Rep 7: 599-604, 2006.

26. Guo JM, Chen HL, Wang GM, Zhang YK and Narimatsu H: Expression of UDP-GalNAc:polypeptide $\mathrm{N}$-acetylgalactosaminyltransferase-12 in gastric and colonic cancer cell lines and in human colorectal cancer. Oncology 67: 271-276, 2004

27. Chuang CY,Lord MS, Melrose J, Rees MD, Knox SM, Freeman C, Iozzo RV and Whitelock JM: Heparan sulfate-dependent signaling of fibroblast growth factor 18 by chondrocyte-derived perlecan. Biochemistry 49: 5524-5532, 2010.

28. Cortes M, Baria AT and Schwartz NB: Sulfation of chondroitin sulfate proteoglycans is necessary for proper Indian hedgehog signaling in the developing growth plate. Development 136 1697-1706, 2009.

29. Bennett EP, Mandel U, Clausen H, Gerken TA, Fritz TA and Tabak LA: Control of mucin-type O-glycosylation: A classification of the polypeptide GalNAc-transferase gene family. Glycobiology 22: 736-756, 2012.

30. Lin MT, Luján R, Watanabe M, Adelman JP and Maylie J: SK2 channel plasticity contributes to LTP at Schaffer collateral-CA1 synapses. Nat Neurosci 11: 170-177, 2008.

31. Funabashi K, Ohya S, Yamamura H, Hatano N, Muraki K, Giles W and Imaizumi Y: Accelerated $\mathrm{Ca}^{2+}$ entry by membrane hyperpolarization due to $\mathrm{Ca}^{2+}$-activated $\mathrm{K}^{+}$channel activation in response to histamine in chondrocytes. Am J Physiol Cell Physiol 298:C786-C797, 2010.

This work is licensed under a Creative Commons Attribution-NonCommercial-NoDerivatives 4.0 International (CC BY-NC-ND 4.0) License. 